\title{
Complex Formation of Resorufin and Resazurin with B-Cyclodextrins: Can Cyclodextrins Interfere with a Resazurin Cell Viability Assay?
}

\author{
Rita Csepregi 1,2 ${ }^{1}$, Beáta Lemli ${ }^{2,3,4}$, Sándor Kunsági-Máté ${ }^{2,3,4}$, Lajos Szente ${ }^{5}$, Tamás Kőszegi 1,2, \\ Balázs Németi ${ }^{6}$ and Miklós Poór ${ }^{2,6, *}$ \\ 1 Department of Laboratory Medicine, University of Pécs, Medical School, Pécs H-7624, Hungary; \\ ritacsepregi93@gmail.com (R.C.); koszegi.tamas@pte.hu (T.K.) \\ 2 János Szentágothai Research Center, University of Pécs, Pécs H-7624, Hungary; \\ lemli.beata@gytk.pte.hu (B.L.); kunsagi-mate.sandor@gytk.pte.hu (S.K.-M.) \\ 3 Department of General and Physical Chemistry, University of Pécs, Pécs H-7624, Hungary \\ 4 Department of Pharmaceutical Chemistry, University of Pécs, Faculty of Pharmacy, Pécs H-7624, Hungary \\ 5 CycloLab Cyclodextrin Research \& Development Laboratory, Ltd., Budapest H-1097, Hungary; \\ szente@cyclolab.hu \\ 6 Department of Pharmacology, University of Pécs, Faculty of Pharmacy, Pécs H-7624, Hungary; \\ balazs.nemeti@aok.pte.hu \\ * Correspondence: poor.miklos@pte.hu; Tel.: +36-72-536-000 (ext. 31646)
}

Received: 8 January 2018; Accepted: 8 February 2018; Published: 10 February 2018

\begin{abstract}
Resazurin (or Alamar Blue) is a poorly fluorescent dye. During the cellular reduction of resazurin, its highly fluorescent product resorufin is formed. Resazurin assay is a commonly applied method to investigate viability of bacterial and mammalian cells. In this study, the interaction of resazurin and resorufin with $\beta$-cyclodextrins was investigated employing spectroscopic and molecular modeling studies. Furthermore, the influence of $\beta$-cyclodextrins on resazurin-based cell viability assay was also tested. Both resazurin and resorufin form stable complexes with the examined $\beta$-cyclodextrins $\left(2.0-3.1 \times 10^{3}\right.$ and $1.3-1.8 \times 10^{3} \mathrm{~L} / \mathrm{mol}$ were determined as binding constants, respectively). Cells were incubated for 30 and $120 \mathrm{~min}$ and treated with resazurin and/or $\beta$-cyclodextrins. Our results suggest that cyclodextrins are able to interfere with the resazurin-based cell viability assay that presumably results from the following mechanisms: (1) inhibition of the cellular uptake of resazurin and (2) enhancement of the fluorescence signal of the formed resorufin.
\end{abstract}

Keywords: resazurin; resorufin; cyclodextrin; host-guest interaction; Alamar Blue; cell viability assay

\section{Introduction}

Resazurin (7-hydroxy-3H-phenoxazin-3-one 10-oxide) also called Alamar Blue is a dye commonly used for measurements assaying cell viability [1-3]. Resazurin itself is weakly fluorescent; however, its reduction by bacteria or mammalian cells results in a pink and highly fluorescent derivative resorufin (7-hydroxy-3H-phenoxazin-3-one) that is formed (Figure 1) [4]. Resorufin in turn can be reduced further into the colorless and non-fluorescent hydroresorufin [5]. The resazurin assay is applied commonly to investigate antibiotic resistance of some bacteria (e.g., Mycobacterium strains), to test the antibacterial action of various compounds, or even to examine bacterial biofilm formation [6-8]. On comparing with other assays testing cell viability, the resazurin-based assay appears suitable and reliable for investigating the toxic effect of various compounds on mammalian cells $[2,9,10]$. Based on previous studies, there is a direct correlation between the reduction of resazurin and the number/proliferation of bacteria or mammalian cells [5]. The resazurin or Alamar Blue assay is used commonly for testing cell viability because its cost is low, and we do not need to extract the cells, owing 
to the much lower cytotoxicity of resazurin and its derivatives than of the reagents employed in other assays, including the commonly applied MTT assay [5]. Resazurin assay itself is a simple and rapid method to test cell viability. Resazurin solution is added to the cells in a volume corresponding to $10 \%$ of the medium (without replacing the medium), and then the conversion to resorufin can be measured by either colorimetry or fluorimetry. Nevertheless, fluorimetry appears more sensitive compared to the colorimetric analysis [5]. The fluorescence excitation and emission maxima of resorufin are approximately at $570 \mathrm{~nm}$ and $585 \mathrm{~nm}$, respectively [11]. However, during the resazurin-based viability assay, the fluorescence of the formed resorufin is determined in the samples using 530 to $580 \mathrm{~nm}$ as excitation and 570 to $620 \mathrm{~nm}$ as emission wavelengths $[3,10,12]$.

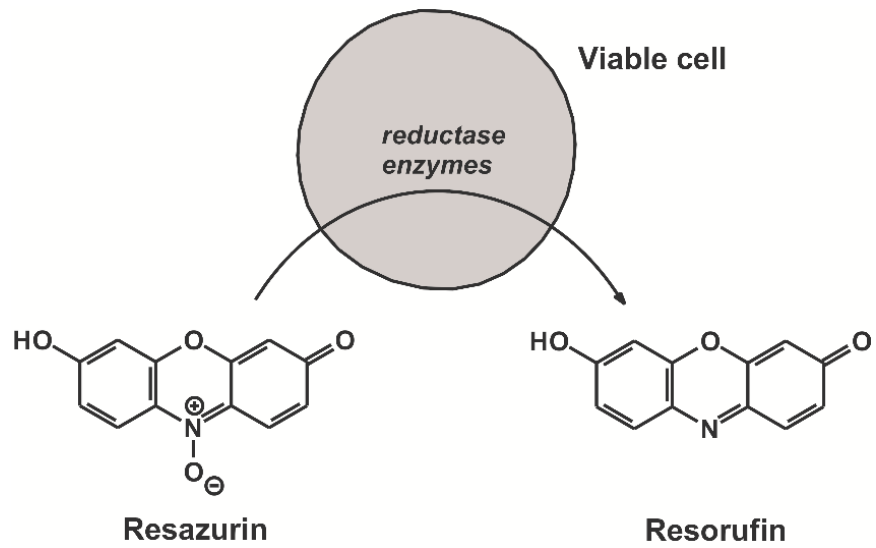

Figure 1. Chemical structures of resazurin and resorufin. Reductases of viable cells reduce resazurin resulting in the formation of its highly fluorescent metabolic product resorufin.

Cyclodextrins (CDs) are intensively studied host molecules that are widely applied by analytical chemistry as well as food, cosmetic, and pharmaceutical industries [13-16]. The usually employed CDs are $\alpha_{-}, \beta-$, and $\gamma$-cyclodextrins, which are built up from six, seven, or eight glucopyranose units, respectively $[17,18]$. CDs possess a ring-shaped, conical structure with a hydrophobic interior and a hydrophilic exterior spaces, which makes their internal cavity able to accommodate relatively lipophilic molecules or structural moieties. The stability of the formed host-guest type complexes as well as the selectivity of CDs towards the guest molecules are usually highly influenced by chemical modifications of the basic CD structures [18,19].

Based on previous investigations, resazurin forms a stable complex with $\gamma$-CD [20], and resorufin interacts with native $\beta$ - and $\gamma$-cyclodextrins [21-23]. CDs are able to influence the cellular uptake of the guest molecules [24]; furthermore, CD-complexes of fluorophore molecules commonly exhibit stronger fluorescence than the fluorophore alone $[25,26]$. A recent study reported that the presence of CDs can interfere with bioluminescence imaging due to complex formation with D-luciferin [27]. Therefore, CDs may also be able to disturb the measurement of other fluorescent dye molecules, including resorufin. CDs can occur in several in vitro experiments carried out on cells where the resazurin-based assay is applied to test cell viability [28-30]. The basic protocol of the resazurin assay applies addition of $10 \%$ volume of resazurin solution to the cell medium without the replacement of the medium. This, however, may result in the interaction of CDs with resazurin and/or the formed resorufin. Even if many researchers replace the cell media (and thus the CDs present) before resazurin assay, methylated CDs can be taken up by cells through fluid-phase endocytosis [31], resulting in the possible formation of resazurin-CD and resorufin-CD complexes intracellularly.

In this study, the complex formation of resorufin and the parent compound resazurin with $\beta$-cyclodextrin (BCD), hydroxypropyl- $\beta$-cyclodextrin (HPBCD), and heptakis-2,6-di-Omethyl- $\beta$-cyclodextrin (DIMEB) was investigated employing fluorescence and UV-Vis spectroscopy. The fluorescence enhancement of resorufin by CDs as well as the stability of the formed resorufin-CD 
complexes were determined, and the interaction was investigated further by molecular modeling studies. Then resazurin-CD and resorufin-CD complex formations were examined employing UV-Vis spectroscopy. Because our spectroscopic studies suggested the strong fluorescence enhancement of resorufin by CDs as well as the formation of stable dye-CD complexes, the effect of CDs on resazurin-based cell viability assay was also tested. As the results demonstrate, some of the CDs are able to interfere with resazurin assay. Therefore, it should also be taken into account that when assaying cell viability, CDs present in the medium could potentially confound the data obtained.

\section{Results and Discussion}

\subsection{Fluorescence Spectroscopic Investigation of Resorufin-CD Interactions}

First, the concentration dependent effect of $\mathrm{CDs}$ on the fluorescence signal of resorufin was examined at $25^{\circ} \mathrm{C}$. Therefore, increasing concentrations of BCD, HPBCD, and DIMEB $(0-1200 \mu \mathrm{M})$ were added to a fixed concentration of resorufin $(0.4 \mu \mathrm{M})$ in phosphate-buffered saline (PBS, pH 7.4). Fluorescence emission spectra were recorded using $570 \mathrm{~nm}$ as excitation wavelength (this wavelength proved the excitation maximum of resorufin; see in Figure S1). As Figure 2 demonstrates, the fluorescence signal of resorufin increased in the presence of each $\mathrm{CD}$ in a concentration dependent fashion. The strongest fluorescence enhancement of resorufin was observed with DIMEB, while in the presence of $B C D$ and $H P B C D$, the fluorescence enhancement was weaker. Furthermore, a red shift of the emission maximum of resorufin was observed in the presence of each of the three CDs (HPBCD > DIMEB > BCD). Under the applied conditions, CDs alone did not express any fluorescence signal; therefore, it is reasonable to hypothesize that the fluorescence enhancement of resorufin by $\mathrm{CDs}$ is ascribable to the host-guest type complex formation of the examined compounds. The microenvironment within the cyclodextrin cavity is less polar than in water; its dielectric properties are close to those of $70 \% v / v$ ethanol-water mixture. The fluorescence signal of a fluorophore is strongly influenced by polarity of the environment around the molecule. In the CD nanocavity, the fluorophore is surrounded by apolar microenvironment, thus affecting its fluorescence due to the molecule being entrapped by the CD. Based on these principles, complex formation of a fluorophore with a CD is commonly associated with the increase of its fluorescence signal $[25,26]$. Furthermore, the methylation of BCD has two consequences: (1) the cavity depth is extended in both primary and secondary side of the cyclinder, which becomes taller, while cavity diameter is unchanged and (2) self-assembly-related poor aqueous solubility of parent BCD is dramatically improved by methylation (intermolecular $\mathrm{H}$-bond formation is disrupted by methyl groups).

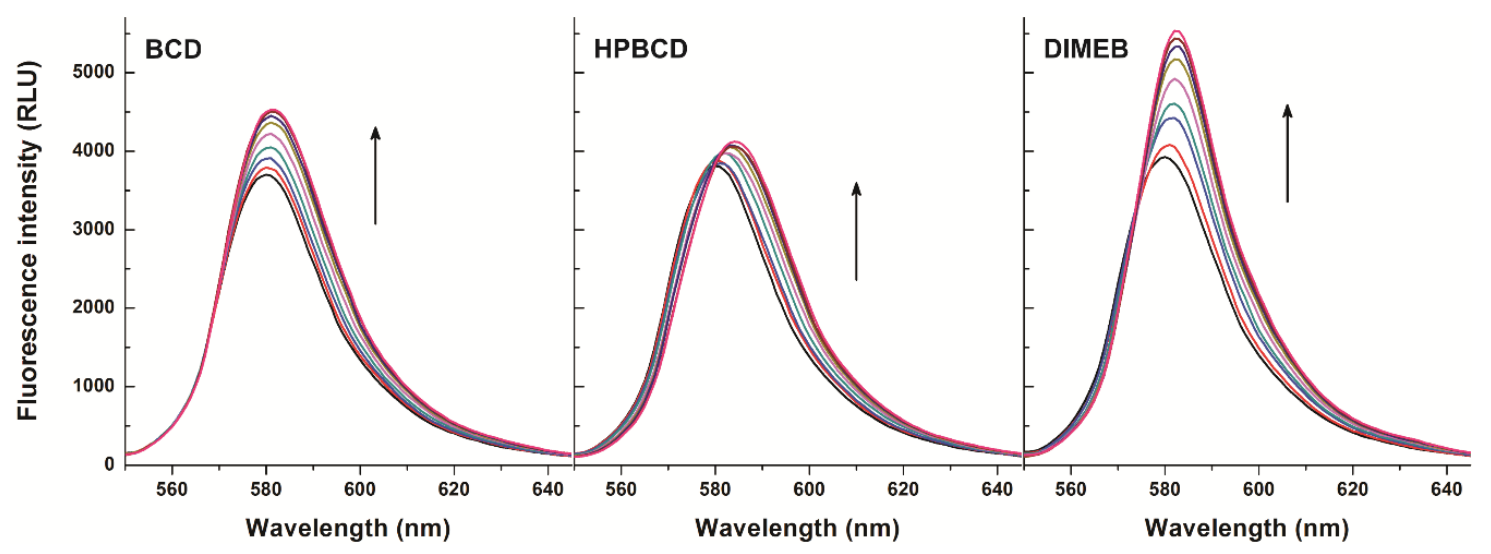

Figure 2. Fluorescence emission spectrum of resorufin $(0.4 \mu \mathrm{M})$ in the presence of cyclodextrins (CDs) added at concentrations $0,50,100,200,400,600,800,1000$, and $1200 \mu \mathrm{M}$ in PBS (pH 7.4; $\left.\lambda_{\mathrm{ex}}=570 \mathrm{~nm}\right)$ (RLU = relative light unit). 
Enhancement of the fluorescence emission intensity of resorufin was evaluated at three emission wavelengths $(580,585$, and $590 \mathrm{~nm})$. As Table 1 demonstrates, in the presence of $0.4 \mu \mathrm{M}$ resorufin and $1200 \mu \mathrm{M}$ of CDs $22-38 \%, 1-39 \%$, and 37-53\% increases of the fluorescence signal of resorufin were noticed as a result of the complex formations with BCD, HPBCD, and DIMEB, respectively. These observations suggest that during resazurin-based cell viability assays CDs can interact with the formed resorufin. This complex formation, however, leads to a significant increase of the fluorescence signal. Considering the fluorescence enhancement of resorufin by CDs, the resorufin-CD interaction can most likely confound the results of the resazurin-based cell viability assay. This phenomenon may be the most prominent with DIMEB because, being a methylated CD molecule, cells take it up by fluid-phase endocytosis [31]. Moreover, as demonstrated in Table 1, DIMEB induced the strongest fluorescence enhancement of resorufin at each tested emission wavelengths, complicating the evaluation of data even further. With respect to the other CDs tested, they have not been reported to cross the cell membrane, likely limiting their presence to the cell medium.

Table 1. Fluorescence enhancement $\left(\mathrm{I} / \mathrm{I}_{0}\right)$ of resorufin $(0.4 \mu \mathrm{M})$ in the presence of cyclodextrins $(\mathrm{CDs})$ $\left(1200 \mu \mathrm{M}\right.$ each) at different emission wavelengths $\left(\lambda_{\mathrm{ex}}=570 \mathrm{~nm}\right)$, and decimal logarithmic values of the binding constants $\left(K\right.$; with the unit of $\mathrm{L} / \mathrm{mol}$ ) of resorufin-CD complexes at 25 and at $37^{\circ} \mathrm{C}$ calculated from the fluorescent spectroscopic studies $\left(\lambda_{\mathrm{ex}}=570 \mathrm{~nm}, \lambda_{\mathrm{em}}=583 \mathrm{~nm}\right.$; mean $\pm \mathrm{SD}$ in 3 separate determinations).

\begin{tabular}{cccccc}
\hline & $\left.\mathbf{I} / \mathbf{I}_{\mathbf{0}} \mathbf{( 5 8 0} \mathbf{~ n m}\right)$ & $\left.\mathbf{I} / \mathbf{I}_{\mathbf{0}} \mathbf{( 5 8 5} \mathbf{~ n m}\right)$ & $\left.\mathbf{I}_{\mathbf{0}} \mathbf{( 5 9 0} \mathbf{~ n m}\right)$ & $\mathbf{l o g} \boldsymbol{K}\left(\mathbf{2 5}{ }^{\circ} \mathbf{C}\right)$ & $\log \boldsymbol{K}\left(\mathbf{3 7}{ }^{\circ} \mathbf{C}\right)$ \\
\hline BCD & $1.22( \pm 0.02)$ & $1.30( \pm 0.02)$ & $1.38( \pm 0.02)$ & $3.31( \pm 0.08)$ & $3.09( \pm 0.03)$ \\
HPBCD & $1.01( \pm 0.01)$ & $1.20( \pm 0.01)$ & $1.39( \pm 0.02)$ & $3.37( \pm 0.05)$ & $3.26( \pm 0.05)$ \\
DIMEB & $1.37( \pm 0.04)$ & $1.52( \pm 0.04)$ & $1.53( \pm 0.03)$ & $3.59( \pm 0.04)$ & $3.52( \pm 0.05)$ \\
\hline
\end{tabular}

The fluorescence of the resorufin-CD complexes was significantly stronger than that of the dye molecule in its free form. Based on the enhanced fluorescence of resorufin in the presence of increasing CD concentrations (Figure 3, left), the binding constants of the formed complexes were calculated employing the graphical application of the Benesi-Hildebrand Equation (Equation (1)). Benesi-Hildebrand plots of resorufin-CD complexes were linear and correlated with the 1:1 stoichiometry model well (Figure 3, right). The calculated binding constants of the tested resorufin-CD complexes indicated similar stability values; however, HPBCD and DIMEB formed more stable complexes with resorufin compared to the native BCD molecule (Table 1). Our results are in good agreement with the previously published data of Balabai et al. [21], where similar $\log K$ value of resorufin-BCD complex $(\log K=3.3)$ and 1:1 stoichiometry of complex formation were reported.
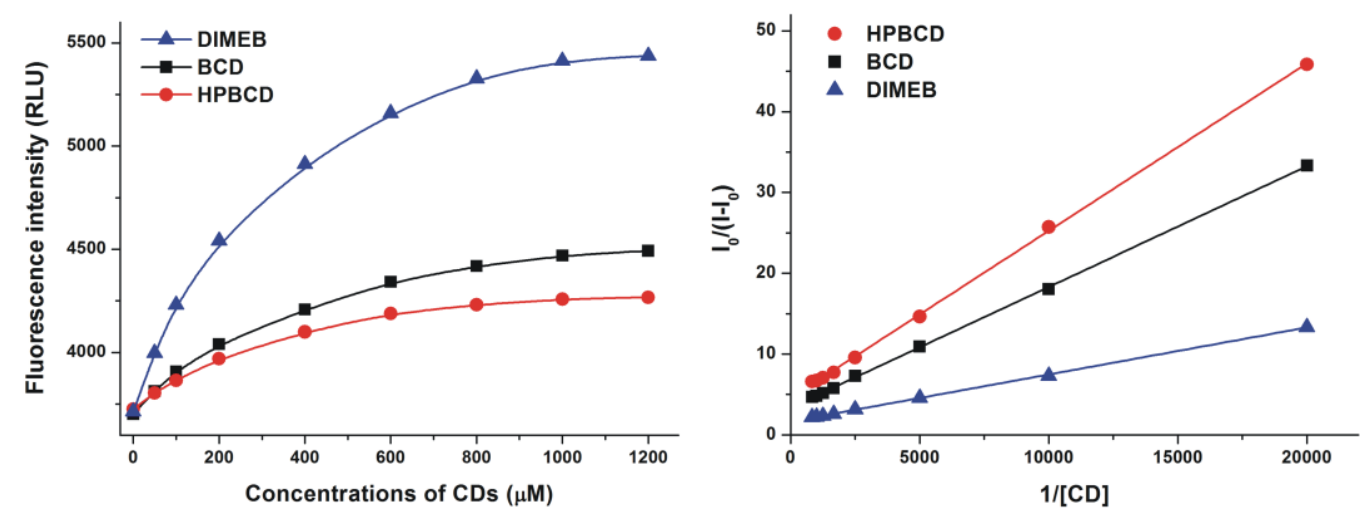

Figure 3. Fluorescence emission intensities (left) of resorufin $(0.4 \mu \mathrm{M})$ in the presence of increasing $\beta$-cyclodextrin (BCD), hydroxypropyl- $\beta$-cyclodextrin (HPBCD), and heptakis-2,6-di-O-methyl$\beta$-cyclodextrin (DIMEB) concentrations in PBS (pH 7.4; left). Benesi-Hildebrand plots of resorufin-CD complexes (right; $\lambda_{\mathrm{ex}}=570 \mathrm{~nm}, \lambda_{\mathrm{em}}=583 \mathrm{~nm}$ ) (RLU = relative light unit). 
Because the incubation of cells with resazurin during the viability assay is carried out at $37^{\circ} \mathrm{C}$, resorufin-CD complex formations were investigated at $37^{\circ} \mathrm{C}$ as well. The stability of the complexes was lower at $37^{\circ} \mathrm{C}$ than at $25^{\circ} \mathrm{C}$, irrespective of the $\mathrm{CD}$ tested. The stability of the resorufin-DIMEB complex weakened minimally, whereas the stability of the resorufin complexes with the other two CDs exhibited a more pronounced, although still slight, reduction (Table 1 ). These findings indicate that we can count on similar stability of the resorufin-CD complexes at $37^{\circ} \mathrm{C}$ as at $25^{\circ} \mathrm{C}$.

\subsection{Molecular Modeling of Resorufin-CD Interactions}

Host-guest interactions are known to be associated with the loss of solvent shell of guest molecules and host's cavity becoming empty prior to the molecular association. Since the experimental results alone cannot confirm the dehydration of the guest molecules, both situations (hydrated or dehydrated guest) were considered during molecular modeling. Accordingly, three series of calculations were performed: (1) the dehydration was ignored during the determination of the enthalpy and entropy changes of the molecular interactions; (2) the dehydration of the guest molecules was considered and calculated by the TIP3P model; and (3) both the dehydration and the energy cost associated to the exit of water molecules from BCD and DIMEB cavities prior the interaction with the resorufin molecules were considered (Table 2).

Table 2. Thermodynamic parameters of resorufin-BCD and resorufin-DIMEB complexes, ignoring the dehydration of guest molecules prior to the interaction (top), considering the outer dehydration of the guest molecules prior to the interaction (middle), or considering both the dehydration of the guest molecules and dehydration of the host's cavity prior to the interaction (bottom).

\begin{tabular}{|c|c|c|c|}
\hline \multicolumn{4}{|c|}{ Without dehydration prior to the interaction } \\
\hline & $\Delta H(\mathrm{~kJ} / \mathrm{mol})$ & $\Delta S(\mathrm{~J} / \mathrm{K} \cdot \mathrm{mol})$ & $\Delta G_{298 \mathrm{~K}}(\mathrm{~kJ} / \mathrm{mol})$ \\
\hline resorufin-BCD & -39.3 & 3.0 & -40.2 \\
\hline resorufin-DIMEB & -50.5 & 1.9 & -51.1 \\
\hline \multicolumn{4}{|c|}{ With dehydration of the guest prior to the interaction } \\
\hline & $\Delta H(\mathrm{~kJ} / \mathrm{mol})$ & $\Delta S(\mathrm{~J} / \mathrm{K} \cdot \mathrm{mol})$ & $\Delta G_{298 \mathrm{~K}}(\mathrm{~kJ} / \mathrm{mol})$ \\
\hline resorufin-BCD & -28.4 & 34.6 & -38.8 \\
\hline resorufin-DIMEB & -39.6 & 33.5 & -49.6 \\
\hline \multicolumn{4}{|c|}{ With dehydration of the guest and the host's cavity prior to the interaction } \\
\hline & $\Delta H(\mathrm{~kJ} / \mathrm{mol})$ & $\Delta S(\mathrm{~J} / \mathrm{K} \cdot \mathrm{mol})$ & $\Delta G_{298 \mathrm{~K}}(\mathrm{~kJ} / \mathrm{mol})$ \\
\hline resorufin-BCD ${ }^{1}$ & -9.6 & 35.2 & -20.9 \\
\hline resorufin-DIMEB ${ }^{2}$ & -13.2 & 34.1 & -23.4 \\
\hline
\end{tabular}

${ }^{1}$ Theoretical $\log K$ value at room temperature was 3.52 while the experimental value was $3.33 .{ }^{2}$ Theoretical $\log K$ value at room temperature was 4.09 while the experimental value was 3.55 .

Very similar Gibbs free energy values were obtained at $298 \mathrm{~K}$ in both the hydrated and the dehydrated guest model, clearly showing that the experiments cannot offer information about the hydration state. However, the molecular dynamics simulation are in accordance with the enthalpy-entropy compensation effect associated to the dehydration of the guest: the energy invested to remove the hydration shell of resorufin molecules appears in the entropy gain associated to the molecular interaction. The negative Gibbs free energy changes validated the presence of stable resorufin-BCD and slightly stronger resorufin-DIMEB complexes in the solutions at room temperature. The formation of stable complexes is supported by both the negative enthalpy and the positive entropy terms, independently from the fact whether or not the hydration is considered during the simulations.

The stability values calculated from Gibbs free energy changes (Table 2) are approximately three order of magnitude higher compared to the experimental values. These findings reflect the presence of exchange reactions instead of simple molecular association. To model plausible processes, the 
theoretical calculations were extended for the following model: three water molecules located in the cavity of the BCD or DIMEB leave before the resorufin guest enters into the cavity. Calculations show markedly less enthalpy changes for these exchange reactions, while the entropy values do not change significantly, compared to the $\Delta H$ and $\Delta S$ values associated to the guest dehydration model (Table 2). The reduction of the enthalpy changes can be explained by the breaking of the bonds between the water molecules and the host's cavity, while the unchanged entropy values reflect ordered structure of water molecules both inside and outside the host's cavity. The theoretically calculated stability constants derived from the third model are in good agreement with the experimentally determined data and exhibit the same tendency: the stability of the resorufin-DIMEB complex is higher than that of the resorufin-BCD complex.

In agreement with the well-known enthalpy-entropy compensation effect, the decomposition of the solvation shell of resorufin molecules does not affect the formation of resorufin-BCD or resorufin-DIMEB complexes around room-temperature. The enthalpy-entropy compensation effect is associated to the energy cost of breaking the interaction between the solvent molecules and the solute, during which the solvation shell is dissipated. The entropy gain derived from the increased freedom of solvent molecules becomes released from the solvation shell of the resorufin molecule immediately before the complex formation. On calculation, the protonated and deprotonated forms of resorufin returned the same interaction energy changes (data not shown). This phenomenon is likely due to the inclusion of the benzoquinone-imine moiety, which remains practically unaffected by the presence or absence of the proton of the $\mathrm{OH}$ group (Figure 4).

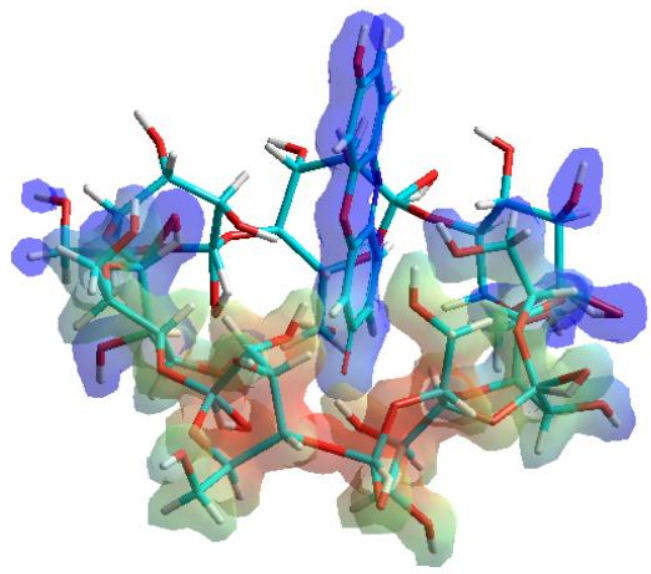

Figure 4. Inclusion complex of the host $\beta$-cyclodextrin (BCD) molecule with the resorufin guest. The complex formation is based on the interaction between the benzoquinone-imine moiety of resorufin molecule and the apolar BCD cavity.

\subsection{Investigation of Resazurin-CD and Resorufin-CD Interactions with $U V$-Vis Spectroscopy}

To confirm the calculated binding constants of resorufin-CD complexes (determined from the data of fluorescence spectroscopy; see in Section 2.1) as well as to investigate the possible formation and stability of resazurin-CD complexes, absorption spectra of resorufin and the parent compound resazurin were recorded in the presence of CDs at $25^{\circ} \mathrm{C}$. CDs $(0-4000 \mu \mathrm{M})$ were added to a fixed concentration of resorufin or resazurin (both $4 \mu \mathrm{M}$ ) in PBS. The absorbance values of both resorufin and resazurin increased together with the increasing CD concentrations (Figures 5 and 6, respectively). Importantly, CDs alone (that is, without resazurin and resorufin) did not have any absorbance at the applied concentrations (data not shown), indicating that the abovementioned increase in the absorbance is most likely due to the interaction of resazurin or resorufin with CDs. In addition, not only absorbance increase but also a slight red shift of the absorption maxima was observed (Figures 5 and 6). These findings suggest that resorufin and resazurin are able to form complexes with CDs. 


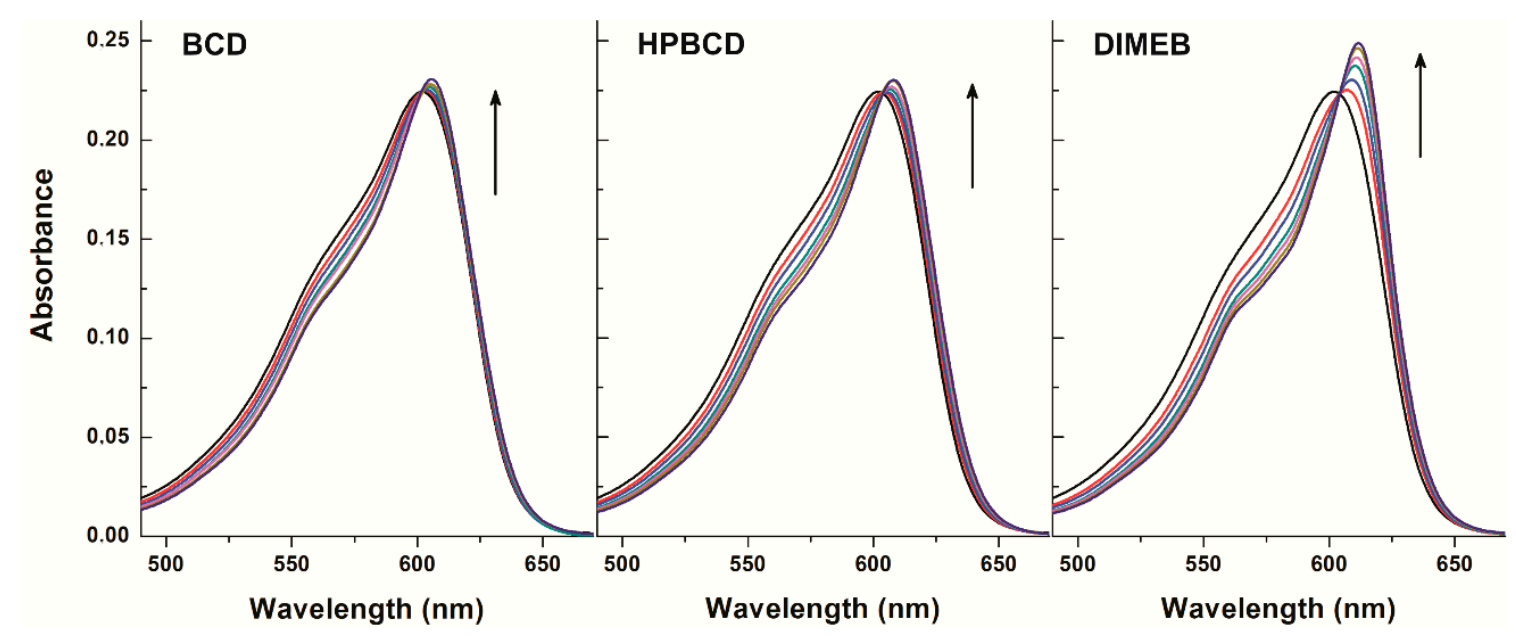

Figure 5. Absorption spectra of resazurin $(4 \mu \mathrm{M})$ in the presence of cyclodextrins (CDs) added at concentrations $0,250,500,1000,1500,2500$, and $4000 \mu \mathrm{M}$ in PBS (pH 7.4).

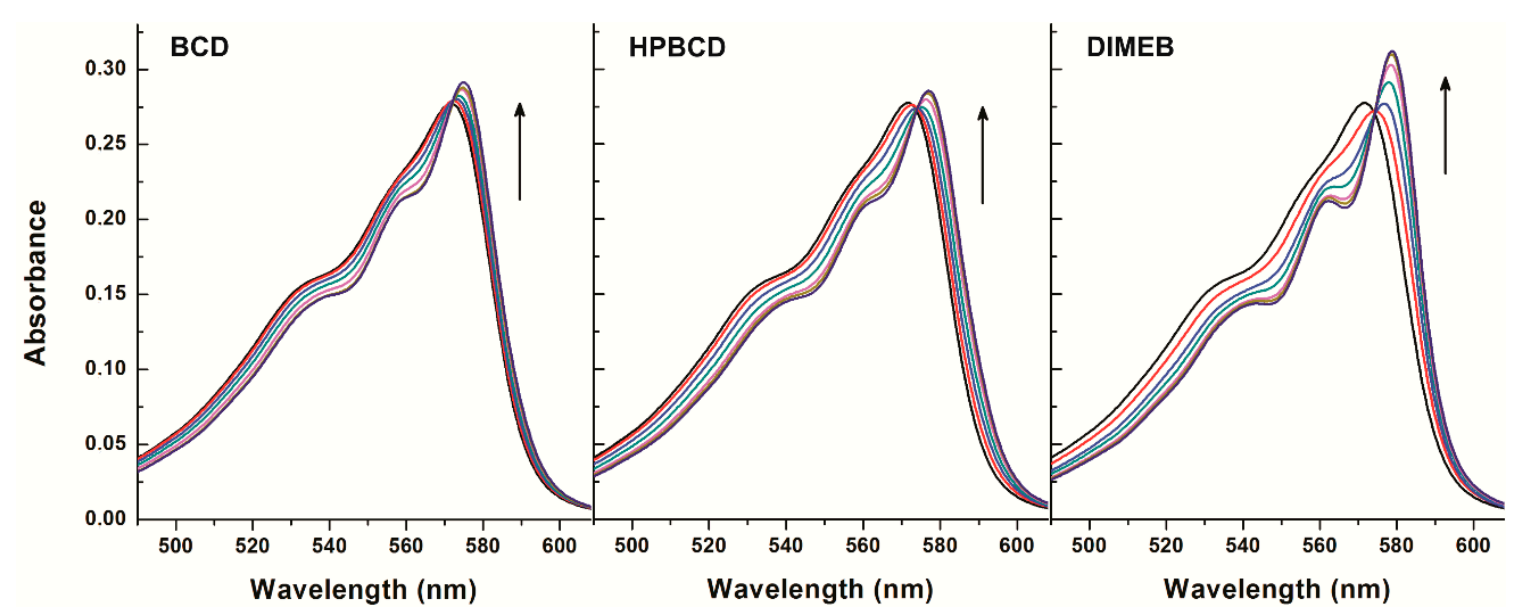

Figure 6. Absorption spectra of resorufin $(4 \mu \mathrm{M})$ in the presence of cyclodextrins (CDs) added at concentrations $0,100,250,500,1000,1500$, and $2000 \mu \mathrm{M}$ in PBS (pH 7.4).

To support this further, binding constants of the resorufin-CD and resazurin-CD complexes were calculated, employing the graphical application of the Benesi-Hildebrand Equation (Equation (1)). As Figure 7 demonstrates, a linear correlation corresponding to 1:1 stoichiometry of the formed complexes was seen. Binding constants of resorufin-CD complexes (Table 3) were in good agreement with from the findings of the fluorescence spectroscopic studies (Table 1). Furthermore, similar $\log K$ values were calculated for the resazurin-CD than for the resorufin-CD complexes (Table 3), confirming the conclusion that resazurin can indeed form complexes with CDs with similar stability than resorufin. These observations strongly suggest that $C D$ s present in cell media are able to influence the cellular uptake of the resazurin through complex formation. The velocity and the extent of the cellular uptake of resazurin is a crucial part of the viability assay because intracellular reductases convert the parent compound resazurin to the highly fluorescent product resorufin. Therefore, CDs may influence resazurin-based cell viability assay in two separate ways: (1) the modified fluorescence intensity of the intracellularly formed resorufin because of its complex formation with CDs (applies only for DIMEB of the tested CDs that is taken up by cells) and (2) the extracellular complex formation of the parent compound resazurin with CDs may also modify the cellular uptake of resazurin. 

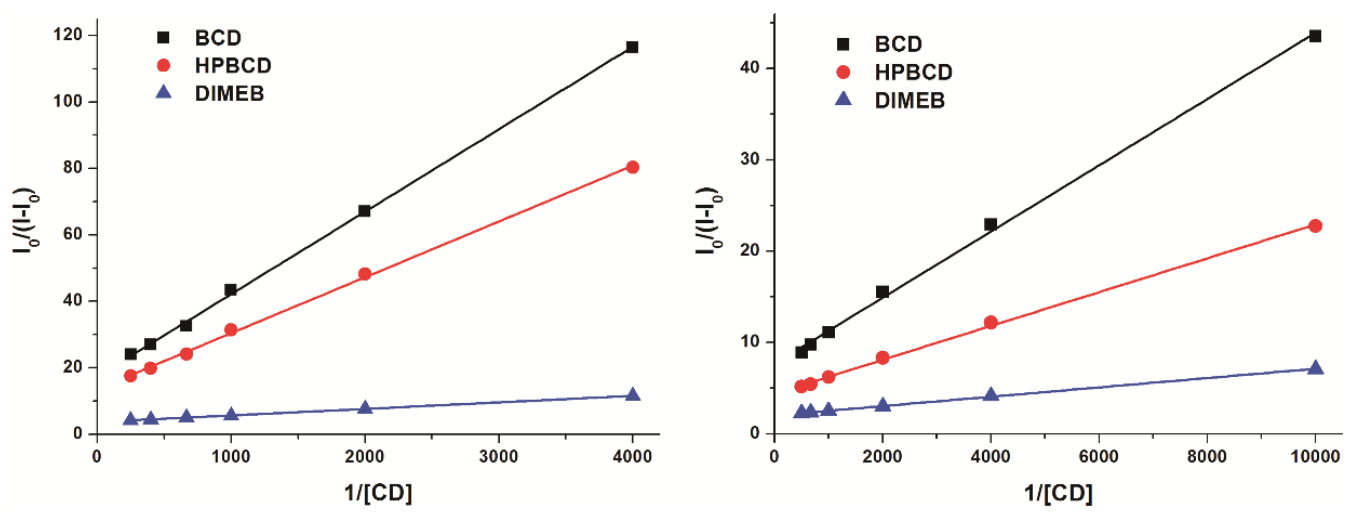

Figure 7. Benesi-Hildebrand plots of resazurin-CD (left; $4 \mu \mathrm{M}$ resazurin $+0,250,500,1000,1500,2500$, and $4000 \mu \mathrm{M}$ concentrations of cyclodextrins (CDs)) and resorufin- $\mathrm{CD}$ (right; $4 \mu \mathrm{M}$ resorufin $+0,100$, $250,500,1000,1500$, and $2000 \mu \mathrm{M}$ concentrations of CDs) complexes (see wavelengths given in Table 3).

Table 3. Decimal logarithmic values of binding constants $(K)$ of resazurin-CD and resorufin-CD complexes calculated from the changes of absorbance of the dye molecules $\left(\lambda_{\text {resazurin-BCD }}=605 \mathrm{~nm}\right.$, $\lambda_{\text {resazurin-HPBCD }}=607 \mathrm{~nm}, \lambda_{\text {resazurin-DIMEB }}=611 \mathrm{~nm}, \lambda_{\text {resorufin-BCD }}=575 \mathrm{~nm}, \lambda_{\text {resorufin- } \mathrm{HPBCD}}=577 \mathrm{~nm}$, $\lambda_{\text {resorufin-DIMEB }}=579 \mathrm{~nm}$; mean $\pm \mathrm{SD}$ in 3 separate determinations).

\begin{tabular}{ccccc}
\hline & \multicolumn{2}{c}{ Resazurin-CD } & \multicolumn{2}{c}{ Resorufin-CD } \\
\hline & $\log K$ & $\lambda_{\max }(\mathrm{nm})$ & $\log K$ & $\lambda_{\max }(\mathrm{nm})$ \\
BCD & $3.13( \pm 0.02)$ & 605 & $3.33( \pm 0.02)$ & 575 \\
HPBCD & $3.15( \pm 0.04)$ & 607 & $3.36( \pm 0.03)$ & 577 \\
DIMEB & $3.25( \pm 0.03)$ & 611 & $3.55( \pm 0.05)$ & 579 \\
\hline
\end{tabular}

2.4. Effects of CDs on Resazurin-Based Cell Viability Assay, and on ATP and Total Protein Levels of HepG2 Cells

To test the effect of CDs on resazurin-based cell viability assay, cells were treated for 30 or $120 \mathrm{~min}$ with $0,0.25,0.5$, and $1.0 \mathrm{mM} \mathrm{CD}$ concentrations in the presence of $2 \mu \mathrm{M}$ resazurin (co-treatment). Furthermore, because CDs may be able to influence the viability of HepG2 cells [25], it was also investigated how treatment of cells separately (first with CDs then, following the removal of CDs from the medium, with resazurin) affects cell viability. Figure 8 demonstrates the results of co-treatments and separate incubations after 30 or $120 \mathrm{~min}$. In the 30-min incubations, 0.5 and $1.0 \mathrm{mM} \mathrm{BCD}$ and HPBCD concentrations led to significantly lower resorufin signals in the co-treated cells than in cells treated separately (where the $\mathrm{CD}$-containing medium was replaced with $\mathrm{CD}$-free medium before the resazurin assay). Similar effect was observed in the presence of $1.0 \mathrm{mM}$ DIMEB, albeit somewhat weaker (Figure 8, left). Based on our current knowledge, CDs are not able to directly influence the cellular action of a compound; however, the entrapment of a guest molecule inside the CD cavity can inhibit its binding to a target structure (e.g., proteins) or can influence the transport of the guest molecule through the cell membrane. Purportedly, CDs reduce the cellular uptake of resazurin and in turn its intracellular conversion to the highly fluorescent derivative resorufin, because CDs are able to form stable complexes with the parent compound resazurin extracellularly (see in Figure 7 and Table 3), preventing its entry into the cell. This idea is supported by the fact that the cellular uptake (including the gastrointestinal absorption) of drugs whose CD complexes are with relatively low binding constants ( $\log K$ is typically 2 to 3 ) is enhanced by CDs [16], while formation of such host-guest complexes with higher binding constants can result in poor cellular uptake of the guest [25]. Thus, the calculated $\log K$ values of resazurin-CD complexes (Table 3) may explain the observed effects. DIMEB brought about smaller differences between the co-treated and the separately treated cells in the 30-min incubations. This might originate from the cellular uptake of DIMEB, because its intracellular 
presence can, at least partly, alleviate the observed $C D$ effects due to enhancing the fluorescence signal of the intracellularly formed resorufin.

The difference observed in 30-min incubations between co-treated and separately treated cells almost completely disappeared in incubations lasting for $120 \mathrm{~min}$, as only minor differences were observed in the presence of $1.0 \mathrm{mM} \mathrm{BCD}$ and $1.0 \mathrm{mM}$ HPBCD concentrations (Figure 8, right). In contrast, DIMEB, instead of weakening the fluorescence seen after $30 \mathrm{~min}$ incubation, increased the signal intensity significantly in cells co-treated with resazurin and DIMEB compared to cells treated separately (Figure 8). This phenomenon is likely due to the enhancement of the fluorescence of the intracellularly formed resorufin by DIMEB, because DIMEB belongs to the methylated CDs, which are known to be taken up by cells through endocytosis, whereas other CDs cannot cross the cell membrane [31]. The longer incubation period can readily result in higher amounts of resorufin formed within and higher amount of DIMEB taken up by the cells, leading to increased intracellular resorufin-DIMEB complex formation and stronger fluorescence enhancement. Interestingly, the difference between co-treated and separately treated cells decreased in response to increasing DIMEB concentrations. This phenomenon may also come from the increased cellular uptake of DIMEB during the $120 \mathrm{~min}$ incubation period. Even if the medium was replaced before resazurin assay, increasing intracellular DIMEB concentrations can result in three consequences: (1) viability loss of HepG2 cells; (2) increased complex formation with resazurin, thus preventing the reduction of the parent compound; and (3) increased fluorescence signal of resorufin due to the complex formation. Since the loss of cell viability and the intracellular resazurin-DIMEB complex formation counter the increased fluorescence signal of resorufin, this can explain why increased DIMEB concentrations led to weaker enhancement of the resorufin signal.

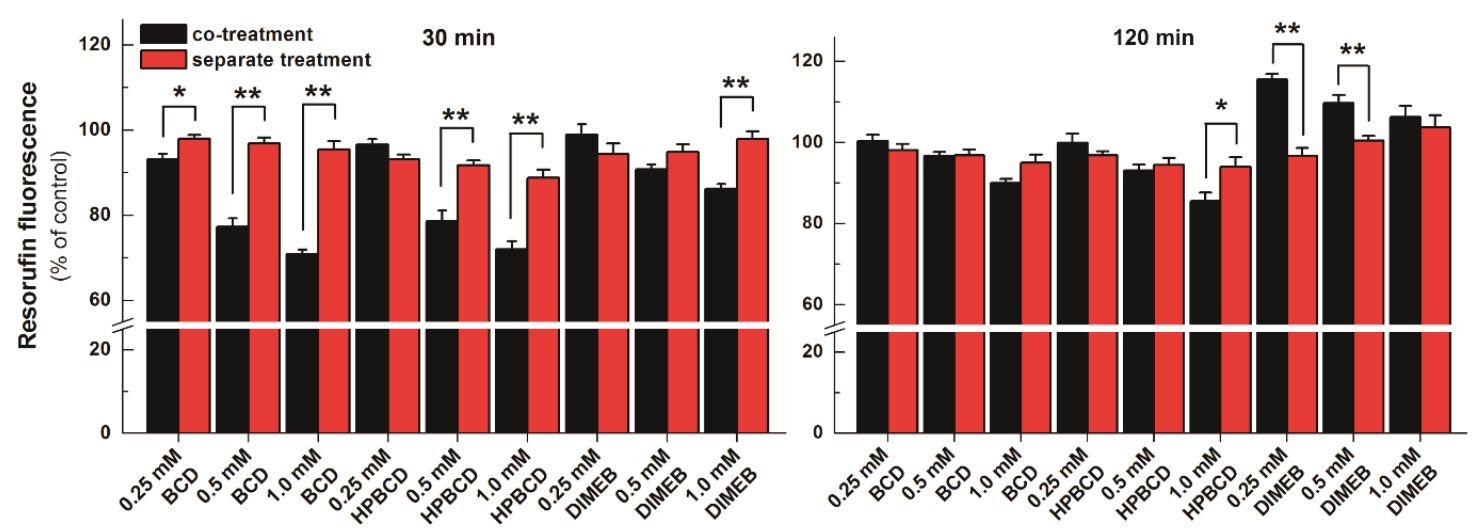

Figure 8. Resazurin-based cell viability assay on HepG2 cells. The cells were incubated with cyclodextrins (CDs) together with resazurin (black bars) or with CDs followed by resazurin (red bars) for $30 \mathrm{~min}$ (left) or $120 \mathrm{~min}$ (right). Bars represent mean \pm SEM of five independent experiments, based on the measurement of resorufin $\left({ }^{*} p<0.05,{ }^{* *} p<0.01\right)$.

In order to test this hypothesis, HepG2 cells were incubated for 30 or 120 min with CDs, and then the medium was removed. The thus obtained cell cultures were used for measuring ATP and total protein levels of cells and the results were compared with the data of the resazurin-based assay. Both ATP and total protein levels showed that CD treatments led to a slight loss of viability of HepG2 cells, correlating well with the resazurin assay in cells treated with BCD or HPBCD (Figure 9). In addition, both ATP and total protein levels suggest the loss of cell viability in the presence of DIMEB, even though this $C D$ caused a concentration-dependent increase of the resorufin signal. These results support the idea that despite DIMEB-containing cell medium was removed from HepG2 cells, during the incubations some DIMEB molecules were taken up by cells. Therefore, the intracellular presence of DIMEB may result in the formation of resorufin-DIMEB complexes that can lead to increased 
fluorescence signal (even though the cell viability suffers some loss), and consequently yields false data in the resazurin-based cell viability assay.

CDs can enhance the aqueous solubility of lipophilic molecules and/or enhance their cellular uptake; therefore, the biological action of CD complexes with different compounds or the cellular uptake of encapsulated guest molecules are commonly tested in cell experiments [32-34]. Because the stability of these CD complexes are typically low, micromolar concentrations of guest molecules should be accompanied by millimolar CD concentrations for achieving encapsulation of the guest at considerable level. Furthermore, CDs (mainly methylated derivatives) are commonly used for manipulate cellular cholesterol content or for extraction of cholesterol from cell membranes [35-37]. During the above-listed experiments, the effects of the encapsulated test compound and of the applied $\mathrm{CD}$ on cell viability need to be tested as well. Since resazurin is a widely used cell viability assay dye, there is a rational chance that researchers choose resazurin to evaluate cell viability.
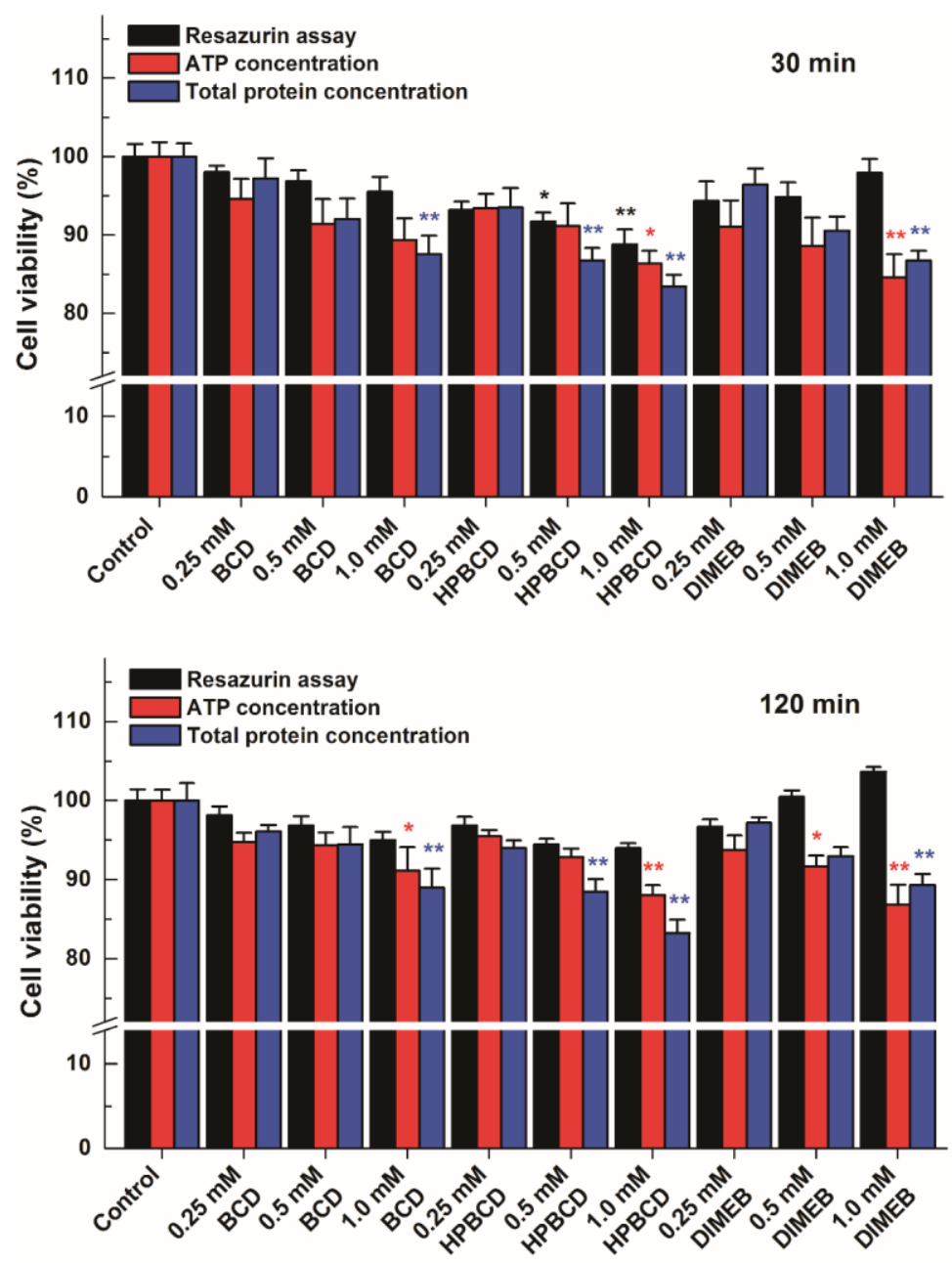

Figure 9. Comparison of the results of the resazurin-based cell viability assay in HepG2 cells treated first with cyclodextrins (CDs) then with resazurin (that is, the CD-containing medium was replaced before addition of resazurin) with the data originating from the changes of intracellular ATP and total protein levels. The cells were incubated for 30 (top) or $120 \mathrm{~min}$ (bottom) with CDs ( $\beta$-cyclodextrin (BCD), hydroxypropyl- $\beta$-cyclodextrin (HPBCD), or heptakis-2,6-di-O-methyl- $\beta$-cyclodextrin (DIMEB)). Bars represent mean \pm SEM of five independent experiments. Asterisks indicate significant difference compared to control incubations with no CD added $\left(* p<0.05,{ }^{* *} p<0.01\right)$. 


\section{Materials and Methods}

\subsection{Reagents}

All reagents were of spectroscopic or analytical grade. Resazurin and resorufin were purchased from Sigma-Aldrich (Waltham, MA, USA). Cyclodextrins, including $\beta$-cyclodextrin (BCD), hydroxypropyl- $\beta$-cyclodextrin (HPBCD; DS (degree of substitution) $=4.5$ ), and heptakis-2,6-di-Omethyl- $\beta$-cyclodextrin (DIMEB; DS = 14), were obtained from CycloLab Cyclodextrin Research \& Development Laboratory (Budapest, Hungary). $1000 \mu \mathrm{M}$ resazurin and $1000 \mu \mathrm{M}$ resorufin stock solutions were prepared in dimethyl sulfoxide (Fluka Analytical, spectroscopic grade, Steinheim, Germany) and stored at $-20^{\circ} \mathrm{C}$, protected from light. Dulbecco's Modified Eagle Medium (DMEM, Sigma-Aldrich, Waltham, MA, USA), Fetal Bovine Serum (FBS, Pan-Biotech, Aidenbach, Germany), Bioluminescent ATP Assay Kit CLSII (Roche, Paris, France), bovine serum albumin (BSA; Biosera, Nuaille, France), and Coomassie Brilliant Blue G-250 (Reanal, Budapest, Hungary) were used as received.

\subsection{Fluorescence Spectroscopic Measurements}

Fluorescence measurements were performed employing a Hitachi F-4500 fluorescence spectrophotometer (Tokyo, Japan). Measurements were carried out at 25 or $37{ }^{\circ} \mathrm{C}$ in phosphate buffered saline (PBS, pH 7.4). During these studies, increasing CD concentrations were added to standard amount of resorufin (final concentrations: resorufin $=0.4 \mu \mathrm{M} ; \mathrm{CDs}=0,50,100,200,400$, $600,800,1000$, and $1200 \mu \mathrm{M}$ ), and then fluorescence emission spectra were recorded using $570 \mathrm{~nm}$ as excitation wavelength. Binding constants of CD complexes were calculated, using the graphical application of Benesi-Hildebrand equation, assuming 1:1 stoichiometry:

$$
\frac{I_{0}}{\left(I-I_{0}\right)}=\frac{1}{A}+\frac{1}{A * K *[C D]^{n}}
$$

where $K$ is the binding constant (with the unit of $\mathrm{L} / \mathrm{mol}$ ), $I_{0}$ and $I$ are fluorescence emission intensities of dye molecules at $583 \mathrm{~nm}$ in the absence and presence of CDs, respectively. [CD] is the molar concentration of CDs in the samples, while $A$ is a constant and $n$ is the number of binding sites.

\subsection{UV-Vis Spectroscopic Measurements}

UV-Vis spectra were recorded using Specord Plus 210 (Analytic Jena AG, Jena, Germany) spectrophotometer. Measurements were carried out at $25^{\circ} \mathrm{C}$ in PBS ( $\mathrm{pH} 7.4$ ). During these studies, CDs at concentrations of $0,250,500,1000,1500,2500$, and $4000 \mu \mathrm{M}$ were added to standard resazurin at a concentration of $4 \mu \mathrm{M}$, and then absorption spectra were recorded. The absorption spectra of resorufin $(4 \mu \mathrm{M})$ were also measured in the presence of CDs at concentrations of 0, 100, 250, 500, 1000, 1500 , and $2000 \mu \mathrm{M}$. Since the complex formation of CDs with resazurin and resorufin results in a slight increase of the absorbance of these dye molecules, binding constants of CD complexes were calculated, employing the graphical application of the Benesi-Hildebrand Equation (Equation (1); see in Section 3.2), where the fluorescence intensity values were replaced with the absorbance values.

\subsection{Modeling Studies}

Semi-empirical AM1 method was applied to determine the initial structures for molecular dynamics simulations. Regarding DIMEB, the structures used for calculations were generated by replacing hydrogens of two $\mathrm{OH}$ groups linked to carbon atoms 2 and 6 of each glucose moieties. Atomic charges of the resorufin molecule and the CDs were calculated using the B3LYP/6-31G(d) method and the basis was set by performing natural population analysis (NPA). Transition states along the reaction path were determined by the HyperChem package (Hypercube, Inc., Gainesville, FL, USA) and the existence of saddle point was validated by the appearance of one virtual vibration frequency. 
Molecular dynamics calculations were performed by modeling the interactions at room-temperature. Both the liquid and gas-phase simulations were performed using the MM+ force field implemented in the HyperChem 8.0 program package. The liquid environment was considered by the TIP3P model. In order to find an appropriate initial condition for the dynamics calculations, a "heating" algorithm implemented in HyperChem was used. This procedure heats the molecular system smoothly from lower temperatures to the temperature $T$, at which the molecular dynamics simulation is performed. The starting geometry for this heating phase is a static initial structure. We used the optimized AM1 geometry of the molecules interacted as initial structures, and the temperature step and the time step in the heating phase were set to $2 \mathrm{~K}$ and $0.1 \mathrm{fs}$, respectively.

Considering the dominance of molecular vibrations in the entropy term associated to the molecular motions, the change of molecular vibrations during the interaction of resorufin and CD molecules was considered to determine the entropy change associated to the complex formation between the resorufin and $C D$ molecules $[38,39]$. The overall effect of vibrations on the entropy changes and the vibrational entropy contents of each species were calculated applying the Boltzmann-statistics. Accordingly, the frequencies were calculated in the harmonic approximation, and the entropy was calculated on the common way using HyperChem code (Equation (2)):

$$
S_{v i b}=R \sum_{i}\left\{\frac{h v_{i} / k T}{e^{\left(h v_{i} / k T\right)}-1}-\ln \left[1-e^{\left(-h v_{i} / k T\right)}\right]\right\}
$$

where $v_{i}$ is the frequency of vibration, $T$ is the temperature (here equals to $298.16 \mathrm{~K}$ ). Considering the known limitation of the procedure above [40], the results are applicable within the temperature range of experiments.

The solvation entropy and enthalpy of resorufin were calculated at semi-empirical AM1 level using TIP3P model implemented in the HyperChem code: entropy content calculated for the gas phase molecule was subtracted from the entropy term of solvated species calculated by the TIP3P model. Similar method was applied for the enthalpy term.

\subsection{Cell Culture}

Adherent cell culture (HepG2, human liver hepatocellular carcinoma, ATCC: HB-8065, Teddington, UK) was cultured in DMEM supplemented with $10 \%$ FBS, penicillin $(100 \mathrm{U} / \mathrm{mL})$ and streptomycin $(100 \mu \mathrm{g} / \mathrm{mL})$, and incubated at $37^{\circ} \mathrm{C}$ in a humidified atmosphere containing $5 \% \mathrm{CO}_{2}$. Cells were then trypsinized and plated into 96 -well sterile plastic plates $\left(10^{4}\right.$ cells/well). After reaching $80 \%$ confluency, the culture medium was replaced with fresh medium containing one of the appropriate concentrations $(0,0.25 \mathrm{mM}, 0.5 \mathrm{mM}$, and $1.0 \mathrm{mM})$ of the selected CDs (BCD, HPBCD, or DIMEB). Both pre-treatment of cells with $\mathrm{CDs}$ (before the addition of resazurin) and the co-treatment with resazurin and CDs were performed.

\subsection{Resazurin-Based Cell Viability Assay}

In order to test the influence of CDs on resazurin-based cell viability assay, the medium was replaced with fresh DMEM containing $0,0.25,0.5$, and $1.0 \mathrm{mM} \mathrm{CD}$ concentrations $(150 \mu \mathrm{L}$ medium/well). Immediately after the CD treatment, $15 \mu \mathrm{L}$ of $22 \mu \mathrm{M}$ resazurin solution (diluted in DMEM) was added to each well (final concentration of resazurin was $2 \mu \mathrm{M}$ ). Thereafter, cells were incubated for 30 or $120 \mathrm{~min}$ at $37^{\circ} \mathrm{C}$ in the dark then fluorescence emission of the formed resorufin dye was determined in the samples employing a multimode plate reader (Perkin Elmer EnSpire Multimode reader, Waltham, MA, U.S.) using 560 and $590 \mathrm{~nm}$ as excitation and emission wavelengths, respectively.

In order to test the potential viability loss of HepG2 cells resulted from the CD treatment, the experiment described above was repeated with some modifications: (1) Cells were pre-treated with CDs for $30 \mathrm{~min}$ then the medium was removed. Thereafter, cells were washed three times with $200 \mu \mathrm{L}$ PBS then $150 \mu \mathrm{L}$ fresh DMEM and $15 \mu \mathrm{L}$ of $22 \mu \mathrm{M}$ resazurin solution (diluted in DMEM) were added 
to each well. After $30 \mathrm{~min}$ incubation at $37^{\circ} \mathrm{C}$ in the dark, resorufin contents were determined by plate reader. (2) Cells were pre-treated with CDs for $120 \mathrm{~min}$ then the medium was removed. Thereafter, cells were washed three times with $200 \mu \mathrm{L}$ PBS then $150 \mu \mathrm{L}$ fresh DMEM and $15 \mu \mathrm{L}$ of $22 \mu \mathrm{M}$ resazurin solution (diluted in DMEM) were added to each well. After $120 \mathrm{~min}$ incubation at $37^{\circ} \mathrm{C}$ in the dark, resorufin contents were determined by plate reader.

\subsection{Quantitation of Intracellular ATP and Total Protein Levels}

To further demonstrate the effects of CDs on the viability of HepG2 cells following 30 or 120 min incubation with CDs $(0,0.25,0.5$, and $1.0 \mathrm{mM})$, intracellular ATP and total protein levels were quantified employing our previously published method with minor modifications [41]. After CD treatment, cells were washed three times with PBS then $250 \mu \mathrm{L}$ of $5 \%$ perchloric acid (PCA) was added to each well. After $15 \mathrm{~min}$ incubation at room temperature, $150 \mu \mathrm{L}$ of the PCA extracts were transferred into an empty plate and neutralized with $9.13 \%$ potassium hydroxide $(100 \mu \mathrm{L} /$ well), during which samples were kept in ice. After sedimentation of the formed potassium perchlorate precipitate, $10 \mu \mathrm{L}$ of the supernates were pipetted into $100 \mu \mathrm{L}$ ATP reagent, using a white 96-well optical plate. The luminescent ATP measurement was carried out using a plate reader and applying 0.2 second as measuring time.

Intracellular total protein levels were determined using the Bradford reagent [41]. Relative protein concentrations were determined employing a calibration curve of bovine serum albumin (BSA) concentrations as the basis of the comparison. Before measurement, cells were lysed with $1 \mathrm{~mol} / \mathrm{L}$ sodium hydroxide solution (15 min at room temperature) then $20 \mu \mathrm{L}$ lysate was added to $200 \mu \mathrm{L}$ Bradford reagent. The absorbance of the samples was measured at $595 \mathrm{~nm}$ using a plate reader.

\subsection{Statistics}

Means \pm SEM values are derived from at least three independent measurements. Data were analyzed with Student's t-test and one-way ANOVA using IBM SPSS Statistics software (version 21, Armonk, NY, USA) with $p<0.05$ or $p<0.01$ as the level of significance.

\section{Conclusions}

In summary, the interaction of resazurin and its reduced metabolite resorufin was investigated with native and chemically modified $\beta$-cyclodextrins, using fluorescence and UV-Vis spectroscopic, and molecular modeling studies. Each tested CD (BCD, HPBCD, and DIMEB) formed stable complexes with resazurin and resorufin, and the presence $C D$ s led to the fluorescence enhancement of resorufin. These observations give rise to the conclusion that CDs can interfere with resazurin-based cell viability assay. In the present work, the testing of this hypothesis is described, using 30 or 120 min incubation times and cells undergoing co-treatment or separate treatment with resazurin and CDs. Furthermore, the effect of CDs on cell viability was examined also by quantifying intracellular ATP and total protein levels. The results presented suggest that CDs can indeed interfere with the resazurin-based cell viability assay, because CDs are able to affect the cellular uptake of resazurin. Furthermore, DIMEB (likely because of its cellular uptake) can enhance the fluorescence signal of resorufin, despite that the presence of DIMEB at increasing concentrations evokes the loss of viability of HepG2 cells. This study highlights that some CDs are able to return false results in the resazurin assay even if the cell medium is replaced prior to the cell viability assay. Therefore, the application of both CDs and the resazurin-based assay during cell experiments needs to be considered thoroughly.

Supplementary Materials: The following are available online at www.mdpi.com/link, Figure S1: Fluorescence excitation spectrum of resorufin $(0.4 \mu \mathrm{M})$ in PBS (pH 7.4) $\left[\lambda_{\mathrm{em}}=583 \mathrm{~nm}\right]$.

Acknowledgments: The project was supported by University of Pécs in the frame of Pharmaceutical Talent Center program. This work was supported by University of Pécs, Medical School (PTE ÁOK-KA-2015/06 [B.N.] and PTE ÁOK-KA-2016/04 [T.K.]) and by the GINOP-2.3.2-15-2016-00049 grant. B.L. acknowledges the support of the ÚNKP-16-4-III New National Excellence Program of the Ministry of Human Capacities (Hungary). The present scientific contribution is dedicated to the 650th anniversary of the foundation of the University of Pécs, Hungary. 
Author Contributions: Miklós Poór and Lajos Szente conceived and designed the experiments. Rita Csepregi and Miklós Poór performed the fluorescence spectroscopic studies. Beáta Lemli and Balázs Németi carried out UV-Vis studies and evaluated the results of spectroscopic measurements. Sándor Kunsági-Máté performed molecular modeling studies. Rita Csepregi and Tamás Kószegi carried out cell experiments. Miklós Poór, Sándor Kunsági-Máté, and Rita Csepregi wrote the paper. All authors have read, edited, and approved the final version of the paper.

Conflicts of Interest: The authors declare no conflict of interest.

\section{References}

1. Coban, A.Y.; Deveci, A.; Sunter, A.T.; Palomino, J.C.; Martin, A. Resazurin microtiter assay for isoniazid, rifampicin, ethambutol and streptomycin resistance detection in Mycobacterium tuberculosis: Updated meta-analysis. Int. J. Mycobacteriol. 2014, 3, 230-241. [CrossRef] [PubMed]

2. Präbst, K.; Engelhardt, H.; Ringgeler, S.; Hübner, H. Basic colorimetric proliferation assays: MTT, WST, and resazurin. Methods Mol. Biol. 2017, 1601, 1-17. [PubMed]

3. Rodríguez-Corrales, J.Á.; Josan, J.S. Resazurin live cell assay: Setup and fine-tuning for reliable cytotoxicity results. Methods Mol. Biol. 2017, 1647, 207-219. [PubMed]

4. Bueno, C.; Villegas, M.L.; Bertolotti, S.G.; Previtali, C.M.; Neumann, M.G.; Encinas, M.V. The excited-state interaction of resazurin and resorufin with amines in aqueous solutions. Photophysics and Photochemical Reaction. J. Photochem. Photobiol. 2002, 76, 385-390. [CrossRef]

5. O'Brien, J.; Wilson, I.; Orton, T.; Pognan, F. Investigation of the Alamar Blue (resazurin) fluorescent dye for the assessment of mammalian cell cytotoxicity. Eur. J. Biochem. 2000, 267, 5421-5426. [CrossRef] [PubMed]

6. Martin, A.; Palomino, J.C.; Portaels, F. Rapid detection of ofloxacin resistance in Mycobacterium tuberculosis by two low-cost colorimetric methods: Resazurin and nitrate reductase assays. J. Clin. Microbiol. 2005, 43, 1612-1616. [CrossRef] [PubMed]

7. Aguilar-Ayala, D.A.; Cnockaert, M.; André, E.; Andries, K.; Gonzalez-Y-Merchand, J.A.; Vandamme, P.; Palomino, J.C.; Martin, A. In vitro activity of bedaquiline against rapidly growing nontuberculous mycobacteria. J. Med. Microbiol. 2017, 66, 1140-1143. [CrossRef] [PubMed]

8. Van den Driessche, F.; Rigole, P.; Brackman, G.; Coenye, T. Optimization of resazurin-based viability staining for quantification of microbial biofilms. J. Microbiol. Methods 2014, 98, 31-34. [CrossRef] [PubMed]

9. Putnam, K.P.; Bombick, D.W.; Doolittle, D.J. Evaluation of eight in vitro assays for assessing the cytotoxicity of cigarette smoke condensate. Toxicol. In Vitro 2002, 16, 599-607. [CrossRef]

10. Emter, R.; Natsch, A. A fast Resazurin-based live viability assay is equivalent to the MTT-test in the KeratinoSens assay. Toxicol. In Vitro 2015, 29, 688-693. [CrossRef] [PubMed]

11. Kim, M.J.; Pal, S.; Tak, Y.K.; Lee, K.H.; Yang, T.K.; Lee, S.J.; Song, J.M. Determination of the dose-depth distribution of proton beam using resazurin assay in vitro and diode laser-induced fluorescence detection. Anal. Chim. Acta 2007, 593, 214-223. [CrossRef] [PubMed]

12. Czekanska, E.M. Assessment of cell proliferation with resazurin-based fluorescent dye. Methods Mol. Biol. 2011, 740, 27-32. [PubMed]

13. Szente, L.; Szemán, J. Cyclodextrins in analytical chemistry: Host-guest type molecular recognition. Anal. Chem. 2013, 85, 8024-8030. [CrossRef] [PubMed]

14. Bochot, A.; Piel, G. Applications of cyclodextrins for skin formulation and delivery. In Cyclodextrins in Pharmaceutics, Cosmetics and Biomedicine, Current and Future Industrial Applications; Bilensoy, E., Ed.; John Willey \& Sons: Hobboken, NJ, USA, 2011; pp. 159-176.

15. Fenyvesi, É.; Vikmon, M.; Szente, L. Cyclodextrins in food technology and human nutrition: Benefits and limitations. Crit. Rev. Food Sci. Nutr. 2016, 56, 1981-2004. [CrossRef] [PubMed]

16. Jambhekar, S.S.; Breen, P. Cyclodextrins in pharmaceutical formulations II: Solubilization, binding constant, and complexation efficiency. Drug Discov. Today 2016, 21, 363-368. [CrossRef] [PubMed]

17. Szejtli, J. Cyclodextrin Technology; Kluwer: Dordrecht, The Netherlands, 1988.

18. Szente, L.; Szejtli, J. Highly soluble cyclodextrin derivatives: Chemistry, properties, and trends in development. Adv. Drug Del. Rev. 1999, 36, 17-28. [CrossRef]

19. Dodziuk, H. Cyclodextrins and Their Complexes; Wiley-VCH Verlag GmbH \& Co. KGaA: Weinheim, Germany, 2008. 
20. Pal, K.; Mallick, S.; Koner, A.L. Complexation induced fluorescence and acid-base properties of dapoxyl dye with $\gamma$-cyclodextrin: A drug-binding application using displacement assays. Phys. Chem. Chem. Phys. 2015, 17, 16015-16022. [CrossRef] [PubMed]

21. Balabai, N.; Linton, B.; Napper, A.; Priyadarshy, S.; Sukharevsky, A.P.; Waldeck, D.H. Orientational dynamics of $\beta$-cyclodextrin inclusion complexes. J. Phys. Chem. B 1998, 102, 9617-9624. [CrossRef]

22. Douhal, A. Ultrafast guest dynamics in cyclodextrin nanocavities. Chem. Rev. 2004, 104, $1955-1976$. [CrossRef] [PubMed]

23. Hamai, S. Ternary inclusion complexes of $\gamma$-cyclodextrin with resorufin and organic cations in aqueous solution. Bull. Chem. Soc. Jpn. 2007, 80, 1527-1533. [CrossRef]

24. Duchêne, D.; Bochot, A. Thirty years with cyclodextrins. Int. J. Pharm. 2016, 514, 58-72. [CrossRef] [PubMed]

25. Poór, M.; Kunsági-Máté, S.; Sali, N.; Kőszegi, T.; Szente, L.; Peles-Lemli, B. Interactions of zearalenone with native and chemically modified cyclodextrins and their potential utilization. J. Photochem. Photobiol. B 2015, 151, 63-68. [CrossRef] [PubMed]

26. Poór, M.; Matisz, G.; Kunsági-Máté, S.; Derdák, D.; Szente, L.; Lemli, B. Fluorescence spectroscopic investigation of the interaction of citrinin with native and chemically modified cyclodextrins. J. Lumin. 2016, 172, 23-28. [CrossRef]

27. Kumar, J.S.; Miller Jenkins, L.M.; Gottesman, M.M.; Hall, M.D. The drug excipient cyclodextrin interacts with D-luciferin and interferes with bioluminescence imaging. Mol. Imaging 2016, 15, 1-7. [CrossRef] [PubMed]

28. Wang, M.S.; Boddapati, S.; Sierks, M.R. Cyclodextrins promote protein aggregation posing risks for therapeutic applications. Biochem. Biophys. Res. Commun. 2009, 386, 526-531. [CrossRef] [PubMed]

29. Petrov, A.M.; Naumenko, N.V.; Uzinskaya, K.V.; Giniatullin, A.R.; Urazaev, A.K.; Zefirov, A.L. Increased non-quantal release of acetylcholine after inhibition of endocytosis by methyl- $\beta$-cyclodextrin: The role of vesicular acetylcholine transporter. Neuroscience 2011, 186, 1-12. [CrossRef] [PubMed]

30. Ijaz, M.; Matuszczak, B.; Rahmat, D.; Mahmood, A.; Bonengel, S.; Hussain, S.; Huck, C.W.; Bernkop-Schnürch, A. Synthesis and characterization of thiolated $\gamma$-cyclodextrin as a novel mucoadhesive excipient for intra-oral drug delivery. Carbohydr. Polym. 2015, 132, 187-195. [CrossRef] [PubMed]

31. Fenyvesi, F.; Réti-Nagy, K.; Bacsó, Z.; Gutay-Tóth, Z.; Malanga, M.; Fenyvesi, É.; Szente, L.; Váradi, J.; Ujhelyi, Z.; Fehér, P.; Szabó, G.; Vecsernyés, M.; Bácskay, I. Fluorescently labeled methyl- $\beta$-cyclodextrin enters intestinal epithelial Caco-2 cells by fluid-phase endocytosis. PLoS ONE 2014, 9, e84856. [CrossRef] [PubMed]

32. Choi, J.M.; Cho, E.; Lee, B.; Jeong, D.; Choi, Y.; Yu, J.H.; Jung, S. Enhancing bio-availability of B-naphthoflavone by supramolecular complexation with 6,6'-thiobis(methylene)- $\beta$-cyclodextrin dimer. Carbohydr. Polym. 2016, 151, 40-50. [CrossRef] [PubMed]

33. Mohtar, N.; Taylor, K.M.; Sheikh, K.; Somavarapu, S. Design and development of dry powder sulfobutylether-ß-cyclodextrin complex for pulmonary delivery of fisetin. Eur. J. Pharm. Biopharm. 2017, 113, 1-10. [CrossRef] [PubMed]

34. Sali, N.; Csepregi, R.; Kőszegi, T.; Kunsági-Máté, S.; Szente, L.; Poór, M. Complex formation of flavonoids fisetin and geraldol with $\beta$-cyclodextrins. J. Lumin. 2018, 194, 82-90. [CrossRef]

35. Christian, A.E.; Haynes, M.P.; Phillips, M.C.; Rothblat, G.H. Use of cyclodextrins for manipulating cellular cholesterol content. J. Lipid Res. 1997, 38, 2264-2272. [PubMed]

36. Zidovetzki, R.; Levitan, I. Use of cyclodextrins to manipulate plasma membrane cholesterol content: Evidence, misconceptions and control strategies. Biochim. Biophys. Acta 2007, 1768, 1311-1324. [CrossRef] [PubMed]

37. Milles, S.; Meyer, T.; Scheidt, H.A.; Schwarzer, R.; Thomas, L.; Marek, M.; Szente, L.; Bittman, R.; Herrmann, A.; Günther Pomorski, T.; Huster, D.; Müller, P. Organization of fluorescent cholesterol analogs in lipid bilayers-lessons from cyclodextrin extraction. Biochim. Biophys. Acta 2013, 1828, 1822-1828. [CrossRef] [PubMed]

38. Brehm, G.; Reiher, M.; Schneider, S. Estimation of the vibrational contribution to the entropy change associated with the low- to high-spin transition in Fe(phen)2(NCS)2 complexes: Results obtained by IR and Raman Spectroscopy and DFT calculations. J. Phys. Chem. A 2002, 106, 12024-12034. [CrossRef] 
39. Li, Y.; Huszthy, P.; Kunsági-Máté, S. Effect of molecular vibrations on the selectivity character of pyridino-18-crown-6 derivatives towards potassium ion. Chem. Phys. Lett. 2012, 533, 45-49. [CrossRef]

40. Cornish-Bowden, A. Enthalpy-entropy compensation: A phantom phenomenon. J. Biosci. 2002, 27, 121-126. [CrossRef] [PubMed]

41. Sali, N.; Nagy, S.; Poór, M.; Kőszegi, T. Multiparametric luminescent cell viability assay in toxicology models: A critical evaluation. J. Pharmacol. Toxicol. Methods 2016, 79, 45-54. [CrossRef] [PubMed]

Sample Availability: Samples of the compounds BCD, HPBCD, and DIMEB are available from CycloLab Ltd. (L.S.).

(C) 2018 by the authors. Licensee MDPI, Basel, Switzerland. This article is an open access article distributed under the terms and conditions of the Creative Commons Attribution (CC BY) license (http:/ / creativecommons.org/licenses/by/4.0/). 